\title{
Günther Unser
}

Die UNO - Aufgaben und Strukturen der Vereinten Nationen

C.H. Beck Verlag, 5. Aufl., München, 1992, 384 S., DM 19,80

"Was wir suchen, ist die Herrschaft des Rechts, gegründet auf die Zustimmung der Regierten und getragen von der organisierten Meinung der Mehrheit."

Woodrow Wilson, Mount Vemon, 4. Juli 1918

Der Verfasser will mit seinem Buch helfen, die "untergeordneten" Informationen ü ber die UNO in den Vordergrund zu rüken und der Bevölkerung den Aufbau der Organisatoin nahezubringen. Im Vorwort erläutert er sein Anliegen: "Das Taschenbuch versteht sich nicht als wissenschaftliche Analyse, wohl aber als ein der Wissenschaft verpflichteter Leitfaden und als handliches Nachschlagewerk mit völkerrechtlichen, historischen und politologischen Akzenten" (X. VI), was zu Unrecht so bescheiden vorgebracht wird.

Zu Beginn geht Unser, Akademischer Oberrat am Institut für Politische Wissenschaft der Rheinisch-Westfälischen Technischen Hochschule Aachen, auf den Völkerbund ein und vergleicht ihn mit der UNO, wobei er ihn als ein "im wesentlichen mißlungenes Experiment" (S. 17) beurteilt. Diese Kritik wird u.a. von Ca. C. Smuts nicht geteilt, der den Völkerbund als "eine große und edle Leistung [...] von bleibendem Wert" ansah. Zwar scheiterte der Bund - nicht zuletzt daran, daB die USA nicht beitragen -, jedoch war er ein enormer Fortschritt, und die UNO konnte manche seiner Prinzipien übemehmen.

Der Autor analysiert systematisch die Ziele und Grundsätze der UNO und erklärt jedes ihrer Organe sowie Mitgliedschaft, Finanzen, Sitz, Sprachen bis hin zu den zwischenstaatlichen Organisationen in Verbindung mit der UNO und den Sonderorganisationen. Immer wieder verdeutlicht er, daß er nicht nur die "Theorie" der Vereinten Nationen beherrscht, sondern ihm die "Wirklichkeit" ebenso bekannt wie wichtig ist. So übemimmt er im Abschnitt über die Vollversammlung den Ausspruch des ehemaligen Generalsekretärs Pérez de Cuéllar, daß sie eine latente Gefahr der "ungezügelten Rhetorik und der übermäßigen Wiederholungen" berge, und macht beim Thema Sicherheitsrat klar, da $\beta$ die Vetos in der Praxis abweichend vom Wortlaut des Art. 27 (3) UN-Charta funktionieren.

Besonders gelungen und bedeutsam sind seine Exkurse zu den "Friedenssichemden Operationen", zum Thema "Deutschland und die Vereinten Nationen" sowie zu Österreich, der Schweiz und Liechtenstein. Wegen ihrer Aktualität und Brisanz würde man sich manche Themen noch ausführlicher wünschen; trotzdem war z.B. Platz für die Darstellung verschiedener Wege politisch neutraler Staaten in die UNO, wobei insbesondere Informationen über Liechtenstein etwas sind, wonach man sonst vergeblich sucht. Aufgezeigt werden auch wichtige Bonner Aktivitäten der 80er Jahre. Schon aus der Perspektive der 90 er Jahre gesehen gab es erstaunliche Äußerungen. Hans-Dietrich Genscher sagte am 26. September 1985 in seiner Rede vor der 40. Generalversammlung: "Wir brauchen keine neue Charta. Aber wir brauchen einen neuen Geist in den Vereinten Nationen". Diesen neuen Geist brachte zunächst Präsident Gorbatschow ein, dessen spektakuläre Überlegun- 
gen 1987 zu einer grundlegenden Neuorientierung der sowjetischen UN-Politik führten. Diese Uberwindung des Ost-West-Gegensatzes gab den Vereinten Nationen ihre Handlungsfähigkeit zurück und stärkte ihre Instrumente zur Konfliktbeherrschung und Friedenssicherung.

Fünf Jahre (und ein geeintes Deutschland) später versicherte Genscher an gleicher Stelle, das vereinte Deutschland strebe nicht nach Macht, "wohl aber sind wir uns der größeren Verantwortung bewußt, die daraus erwächst" (S. 247). Das darf wohl seit mehr als zwei Jahren bezweifelt werden. Eine politische Grundsatzentscheidung zum Thema "Blauhelmeinsätze" beispielsweise steht immer noch aus. Wodurch Deutschland sich auszeichnet, ist nicht größeres Verantwortungsbewußtsein, sondem eher "verfassungspolitische Horizontschleicherei" (S. 249).

Am Ende zeigt Unser noch einmal chronologisch die einzelnen Entwicklungsphasen der UNO auf, wobei ihm weniger daran liegt, "Erfolge und Mißerfolge aufzuzählen und Zensuren zu verteilen, als vielmehr [...] in groben Strichen ansatzweise die Entwicklung der UNO [...] von der Gründung bis zur Gegenwart nachzuzeichnen" (S. 268). Er charakterisiert den kalten Krieg (1945-1953), den Aufbruch der Dritten Welt (1954-1964), den beginnenden Nord-Süd-Konflikt (1965-1973) sowie dessen spätere Dominanz (1974-1986) und endet mit der "Suche nach der neuen Ordnung" ab 1987.

Der Autor warnt vor Schlagzeilen wie "UN-Renaissance" oder "Morgenröte im Glaspalast" und vor einer allzu "blauäugigen" Beurteilung. Zwar sei in den letzten Jahren viel Positives geschehen, jedoch dürfe nicht vergessen werden, daB z.B. "peace-keeping operations" an manchen Orten wenig Erfolg hätten, daB die Zusammenarbeit immer wieder von einzelnen Staaten untergraben werde, daB die Finanznot erheblich sei - und entscheidend sein könne und vielleicht doch eine Reform der Charta nötig sei, um die Leistungsfähigkeit des Systems zu verbessem.

Das in den 70er Jahren erstmals erschienene Buch "wächst" von Auflage zu Auflage an Umfang und Qualität. Es ist zur Einarbeitung in den Themenkomplex UNO überaus geeignet. Nach einem soliden historischen und "instrumentalen" Ubberblick folgt eine Analyse von Fällen und peace-keeping-Einsätzen. Uberzeugend ist immer wieder das Aufzeigen der Unterschiede zwischen der Theorie der Charta und der Praxis, auf die der Autor großen Wert legt. Eine gewisse Schwäche ist die ausschließlich deutschsprachige Bibliographie, da die führende Literatur zu den meisten Problemkreisen in englischer Sprache verfaßt ist. Allerdings könnte man argumentieren, daB ein "komplettes" Literaturverzeichnis den Rahmen einer solchen Veröffentlichung sprengen würde. An manchen Stellen ist die Wortwahl des Buches "unjuristisch", das jedoch mag die Lektüre für Nicht-Experten erleichtem.

Alles in allem ist die Arbeit Unsers sehr positiv zu bewerten. Sein Buch informiert umfassend und wirklichkeitsnah, ist gut gegliedert, zügig zu lesen und enthält erstaunlich viele Details, sehr viel mehr, als man von einem Taschenbuch erwartet. 